\title{
Operant Sensation Seeking Engages Similar Neural Substrates to Operant Drug Seeking in C57 Mice
}

\author{
Christopher M Olsen ${ }^{1,2,3}$ and Danny G Winder*,1,2,3 \\ 'Department of Molecular Physiology and Biophysics, Vanderbilt University School of Medicine, Nashville, TN, USA; 'Center for Molecular \\ Neuroscience, Vanderbilt University School of Medicine, Nashville, TN, USA; ${ }^{3}$ JF Kennedy Center for Research on Human Development, Vanderbilt \\ University School of Medicine, Nashville, TN, USA
}

\begin{abstract}
Novelty and sensation seeking have been associated with elevated drug intake in human and animal studies, suggesting overlap in the circuitry mediating these behaviors. In this study, we found that C57BI/6J mice readily acquired operant responding for dynamic visual stimuli, a phenomenon we term operant sensation seeking (OSS). Like operant studies using other reinforcers, mice responded on fixed and progressive ratio schedules, were resistant to extinction, and had sustained responding with extended access. We also found that OSS, like psychostimulant self-administration, is sensitive to disruption of dopamine signaling. Low doses of the dopamine antagonist cisflupenthixol increased active lever responding, an effect reported for psychostimulant self-administration. Additionally, DI-deficient mice failed to acquire OSS, although they readily acquired lever pressing for food. Finally, we found that one common measure of novelty seeking, locomotor activity in a novel open field, did not predict OSS performance. OSS may have predictive validity for screening compounds for use in the treatment of drug addiction. In addition, we also discuss the potential relevance of this animal model to the field of behavioral addictions.

Neuropsychopharmacology (2009) 34, 1685-1694; doi:I0.1038/npp.2008.226; published online 14 January 2009
\end{abstract}

Keywords: novelty seeking; self-administration; addiction; motivation; reinforcement; dopamine

\section{INTRODUCTION}

Novelty and sensation seeking have been associated with elevated drug intake in humans (Zuckerman, 1986; Cloninger, 1987), and reactivity to inescapable novelty is associated with increased sensitivity to the reinforcing effects of psychostimulants in rodents, (Piazza et al, 1989). These associations suggest an overlap in the neural substrates that encode the reinforcing values of both of these constructs. Consistent with this notion, novelty and predictable visual stimuli have been shown to serve as reinforcers in rat models, such as place preference (Bardo et al, 1989) and operant behavior (Stewart, 1960; Caggiula et al, 2001; Cain et al, 2006). Like natural (ie, food and sexual cues) and pharmacological (ie, drugs of abuse) reinforcers (for review, see Di Chiara et al, 2004), novel stimuli can also increase mesolimbic dopamine (DA) levels (Rebec et al, 1997). Interestingly, drugs of abuse increase DA levels specifically in the shell subregion (Pontieri et al, 1995; Di Chiara et al, 2004), whereas the natural reinforcers,

*Correspondence: Dr DG Winder, Department of Molecular Physiology and Biophysics, Vanderbilt University School of Medicine, 724B MRB I, Room 750, RRB, 23rd and Pierce Avenue S, Nashville, TN 37232-06 I5, USA, Tel: + 615322 ।|44, Fax: + 615322 1462, E-mail: danny.winder@vanderbilt.edu

Received 22 September 2008; revised II November 2008; accepted 4 December 2008 such as food and sexual cues (Mitchell and Gratton, 1992), only increase DA within the core. Like drugs of abuse, novel stimuli have been shown to elevate DA specifically in the nucleus accumbens (NAc) shell, and not the core (Rebec et al, 1997). Novel food has been shown to increase NAc shell DA levels, but this effect disappears when the food becomes familiar (Bassareo et al, 2002). Disruption of DA signaling also differentially affects reinforcer types. For example, lesion of NAc dopaminergic afferents does not affect self-administration of morphine or food (Dworkin et al, 1988; Caine and Koob, 1994b), but does disrupt selfadministration of cocaine (Caine and Koob, 1994b) and novelty place preference (Pierce et al, 1990). Likewise, D1 receptor-deficient mice fail to self-administer cocaine, but continue to self-administer food and opiates (Caine et al, 2007).

Operant models are powerful in assessing the reinforcing values of a variety of reinforcers and have a high degree of construct and face validity for the study of addiction (O'Brien and Gardner, 2005). To characterize the reinforcing effects of novelty/sensation seeking in an operant model, we tested the ability of varied visual stimuli to support operant responding in $\mathrm{C} 57 \mathrm{Bl} / 6 \mathrm{~J}$ mice. We found that these mice will 'self-administer' varied visual cues without prior training, a task we refer to as operant sensation seeking (OSS). We further characterized OSS using a higher schedule of reinforcement and tested 
resistance to extinction as well as sensitivity to DA signaling. Like cocaine and heroin self-administration, OSS is sustained with extended sessions, and sensation seeking continues under extinction conditions (de Wit and Stewart, 1981, 1983; Ahmed and Koob, 1998; Ahmed et al, 2000). Our results suggest that dynamic stimuli are reinforcing to mice, and encoding of this type of reinforcement may be similar to drug reinforcement as opposed to that of other natural or nondrug reinforcers.

\section{MATERIALS AND METHODS}

\section{Animal Care}

Male C57Bl/6J mice were obtained from Jackson Laboratories (Bar Harbor, ME, USA) at 3 weeks of age. DA D1 receptor $(d r d 1 a)$-deficient mice were bred in house from heterozygous matings of animals backcrossed onto C57Bl/6J background $>14$ generations, and genotypes were determined as described previously (Stanwood et al, 2005). Mice were housed 2-5 per cage in a temperature and humiditycontrolled environment (lights on 0600-1800 h). Mouse cages $(30 l \times 16 w \times 14 d \mathrm{~cm})$ contained corn cob bedding supplemented with a small amount of cellulose bedding (Carefresh). Food and water were available ad libitum unless noted. Mice were handled for 3 days before the beginning of experiments. All procedures were approved by the Animal Care and Use Committee at Vanderbilt University.

\section{Novel Open Field Activity}

Before OSS, mice were tested for open field locomotor activity in a novel environment as described previously (Olsen and Winder, 2006). Mice were tested in a 1-h session using automated experimental chambers $(27.9 \times 27.9 \mathrm{~cm}$; MED-OFA-510; MED Associates, St Albans, VT) under constant illumination within a sound-attenuated room. Analysis of open field activity was performed using activity monitor v5.10 (MED Associates).

\section{Operant Conditioning}

Operant chambers. Operant training chambers are as described by Olsen and Winder(2006), with levers mounted $2.2 \mathrm{~cm}$ above the grid floor and cue lamps (yellow LEDs) mounted $2 \mathrm{~cm}$ above them. At the beginning of each session, the house light and exhaust fan were turned on. In the OSS group, a compound visual/auditory stimulus was presented after completion of the required ratio (detailed below), whereas presses on the inactive lever were counted but had no programed consequence. The compound stimulus was a presentation of flashing cue lights (random duration of $2,4,6$, or $8 \mathrm{~s}$; random flash rate of $0.625,1.25$, 2.5 , or $5 \mathrm{~Hz}$ ), with each flash randomly on the right or left side of the chamber, and the house light was turned off during the visual stimuli. The auditory stimulus was activation of an infusion pump located within the cubicle (no infusion is made). There were no results of pressing either lever in control mice, therefore levers are denoted as 'lever 1' or 'lever 2', and were counterbalanced across chambers.

\section{Experiment 1: Fixed Ratio Operant Responding for Varied Visual Stimuli}

Subjects were tested in 1-h sessions without any prior training or dietary restriction. Active lever assignment (left or right lever) was counterbalanced across animals. Mice received varied visual and auditory stimuli following each active lever press (FR-1), whereas inactive lever presses had no consequence. Initially, eight mice were tested for OSS (Figure 1a). Fifteen additional mice were tested in a replicate study (Figure $1 b-d$ ), this time with the inclusion of a control group ( $\mathrm{C}$ mice) that received no consequence of lever pressing (eight OSS and seven $\mathrm{C}$ mice). As the goal of this experiment was to characterize OSS, no exclusion criteria were set.

\section{Experiment 2: Progressive Ratio (PR) Operant Responding for Varied Visual Stimuli}

A separate cohort of 16 mice tested on a PR schedule of reinforcement. This experiment consisted of three phases: (1) FR-1 OSS, (2) PR OSS, and (3) extinction. After 14 days of FR-1 OSS, mice responded for stimuli on a PR in five daily 2-h sessions. Mice that did not meet acquisition criteria for FR-1 OSS (mean $\geqslant 60 \%$ lever accuracy and $\geqslant 20$ active lever presses during the last five sessions) were removed from the experiment. One mouse was excluded based on this criterion. During PR sessions, the schedule of reinforcement was increased in the following pattern: $1,2,4$, $6,9,12,16,20,25,30$, and so on. (Colby et al, 2003; Olsen and Winder, 2006). To facilitate acquisition of PR, only the active lever was available. To control for any nonspecific increase in lever pressing that could occur due to stimulus presentation, control mice received yoked presentations of the stimuli and their lever pressing (there was no consequence of lever pressing in control mice) was measured. During the PR phase, OSS mice continued to receive visual stimuli as a reinforcer, whereas $\mathrm{C}$ mice received yoked stimuli. Lever responses by $\mathrm{C}$ mice remained without consequence.

Extinction. Following the PR phase, mice were tested for extinction in hourly sessions separated by a 5 -min period (levers were retracted, and the fan and house light were extinguished). During extinction, OSS mice received presentation of the pump sound in response to active lever pressing and there was no result of lever pressing in control mice. Extinction was performed 3-4 days following PR experiments. Extinction continued until a criterion of $\leqslant 20$ active lever presses for 2 consecutive hours was met or the maximum eight sessions had been completed (these mice received a value of eight trials to extinction).

\section{Experiment 3: Effects of DA Antagonism on OSS}

A separate cohort of 16 mice was used to determine the effects of DA antagonism on FR-1 OSS. Mice first underwent 14 sessions, then half of the mice were assigned to the OSS group (FR-1 OSS as described) and half of the mice were in the control group (no consequence of pressing either lever). All mice were habituated to the injection procedure $(10 \mathrm{ml} /$ $\mathrm{kg}$ s.c. $30 \mathrm{~min}$ before the beginning of the session) during 

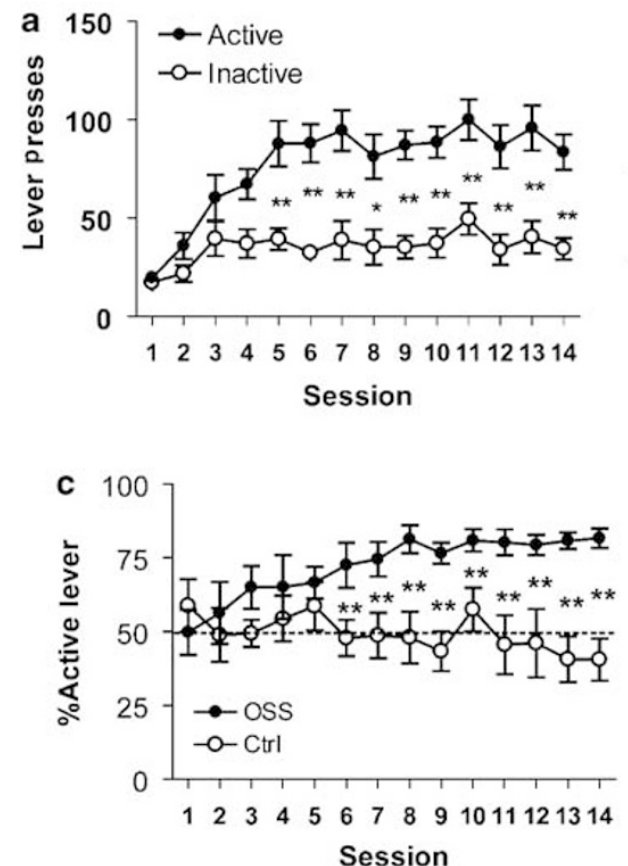
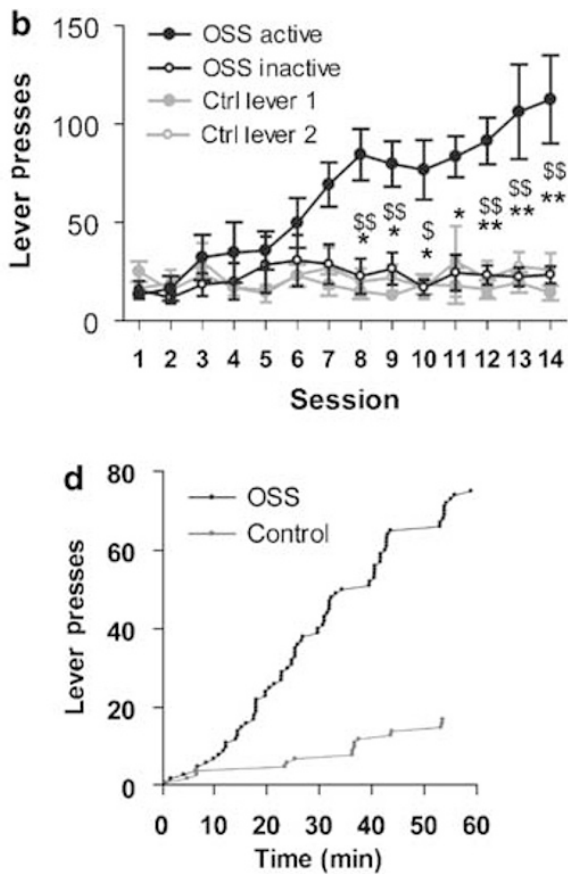

Figure I Mice acquire operant responding for varied visual stimuli. Untrained mice acquired a preference for the active lever delivering dynamic stimuli. (a) Active lever presses were significantly greater than inactive from days $5-14(n=8, * p<0.05$, *** $p<0.01)$. (b) A second cohort also increased active lever pressing relative to inactive lever pressing ( ${ }^{*} p<0.05$, $\left.{ }^{*} p<0.0 \mathrm{I}\right)$ and to nonreinforced lever pressing by controls $\left(n=7-8,{ }^{\$} p<0.05,{ }^{\$ \$} p<0.0 \mathrm{I}\right)$. (c) $\mathrm{OSS}$ mice also showed a significantly greater lever preference than $C$ mice $(* * x<0.0 I$ ). (d) Representative time course from an OSS and $C$ mouse on session I 0.

the last three sessions. Two mice were removed due to not meeting acquisition criteria (see Experiment 2). A final session was performed $30 \mathrm{~min}$ after saline injection for 'baseline' active lever pressing values in OSS and $\mathrm{C}$ mice. cis-(Z)-flupenthixol (Sigma, St Louis, MO, USA) was dissolved in saline and given at doses of 0.01, 0.03, 0.09, 0.15 , and $0.21 \mathrm{mg} / \mathrm{kg}(10 \mathrm{ml} / \mathrm{kg}$ s.c., $30 \mathrm{~min}$ beore) across sessions. Mice received each dose $48 \mathrm{~h}$ apart using a withinsubjects Latin square design, with nondrug (saline injection) OSS sessions run in between doses.

\section{Experiment 4: Effects of DA D1 Receptor Deletion on OSS and Operant Responding for Food}

Nineteen DA D1 receptor (drd1a) null and wild-type (WT) littermate mice underwent 14 FR-1 OSS sessions as described. To characterize performance of all of these mice in OSS, no exclusion criteria were set. To determine whether D1 null mice are capable of acquire FR-1 operant behavior using another reinforcer, a separate cohort of nine D1 null and WT mice were allowed to lever press for food. Mice were food restricted (food available $\sim 6 \mathrm{~h}$ /day) and trained to lever press for food as described (Schramm-Sapyta et al, 2006). Briefly, mice were trained to self-administer $25 \%$ vanilla Ensure on an FR-1 schedule in daily sessions. A session ended when a subject obtained 50 reinforcers or after $1 \mathrm{~h}$.

\section{Experiment 5: Effects of Extended Access on OSS}

A separate cohort of 23 mice was tested for the effects of extended access on OSS. All mice had an initial 10 days of 1-h FR-1 OSS sessions. Four mice did not meet acquisition criteria (mean $\geqslant 60 \%$ lever accuracy and $\geqslant 20$ active lever presses during last two sessions) and were removed from the study. Following the 10 sessions, mice were divided into two groups counterbalanced by the number of active lever presses on day 10: a 1-h access group ( $n=9$ mice) and a 6-h access group $(n=10$ mice). Ten more sessions were run, and then extinction sessions were performed as described 7-9 days following the last OSS session.

\section{Statistical Analysis}

OSS data were analyzed by multivariate repeated measures ANOVA (session (repeated), factor B, lever or group where appropriate, factor $\mathrm{C}$, lever or group where appropriate) followed by Fisher's LSD multiple comparisons. An exception to this is in cis-flupenthixol experiments, where the repeated factor was dose and factor B was group. GamesHowell multiple comparisons were performed when variances were significantly heterogeneous (as measured by Levene's F).

\section{RESULTS}

\section{Mice Acquire Operant Behavior for Novel Visual Stimuli}

Subjects were tested without prior training or dietary restriction on an FR-1 schedule. In response to active lever pressing, mice received varied visual stimuli whereby each reinforcer consisted of flashing of stimulus lamps with random frequencies and durations (see MATERIALS AND METHODS for details). The stimuli supported operant 
behavior as shown by significantly elevated active lever pressing relative to inactive lever pressing across sessions. There were significant main effects of both lever $(\mathrm{F}(1,208)=30.4, p<0.0001)$ and session $(\mathrm{F}(13,208)=10.5$, $p<0.0001)$ as well as an interaction effect $(\mathrm{F}(13,208)=3.5$, $p<0.0001)$ Post hoc tests showed significant differences between levers across several sessions (Figure 1a). We repeated the experiment using separate mice, including a control group, which received no consequence of pressing either lever. Mice receiving visual cues (OSS mice) again acquired operant behavior, whereas controls (C mice) did not (Figure $1 \mathrm{~b}$ and $\mathrm{c}$ ). Three-way ANOVA revealed significant effects of group $(\mathrm{F}(1,390)=17.5, p<0.001)$, lever $(\mathrm{F}(1,390)=11.4, p<0.01)$, and session (repeated factor, $\mathrm{F}(13,390)=6.4, \quad p<0.0001)$. All interactions were also significant $(p<0.0001)$. Figure $1 \mathrm{~d}$ shows the time course of active lever presses by an OSS mouse and lever 1 presses from a control mouse on session 10 .

\section{OSS is Maintained on PR and Is Resistant to Extinction}

To determine whether the novel stimuli would support PR responding on a more demanding schedule, a cohort of mice was tested on a PR following 14 days of FR-1 responding. In daily 2 -h sessions, OSS mice maintained high levels of responding, whereas $\mathrm{C}$ mice responded very little (Figure 2a-c). Comparing lever pressing across sessions (Figure $2 \mathrm{~b}$ ), there was a significant main effect of
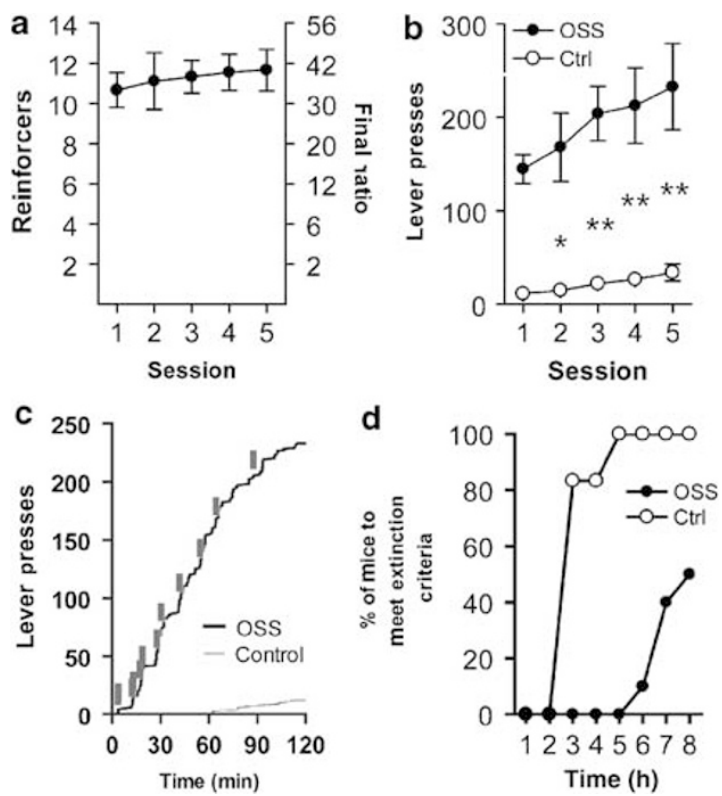

Figure 2 OSS maintains responding on progressive ratio and is resistant to extinction. (a) Number of reinforcers (left $y$-axis) obtained and associated final ratios (right $y$-axis) during five $2 \mathrm{~h}$ sessions. (b) Total active lever presses during sessions depicted in panel a, including control mice. OSS mice had significantly greater lever presses than $C$ mice, which received yoked presentation of reinforcers $(n=6-9 * 0<0.05$, $* * 2<0.01)$. (c) Representative time course from OSS and Ctrl mice on PR day 4. Gray ticks indicate presentation of stimuli in both animals, as this $C$ mouse was yoked to this OSS mouse. (d) Mice continued I h sessions until criteria were met or after eight sessions. Data are plotted as percent of the group to meet criteria for each hour. group $(\mathrm{F}(1,60)=25.5, \quad p<0.001)$, but not session $(\mathrm{F}(4,60)=2.0, \mathrm{NS})$, or interaction $(\mathrm{F}(4,60)=0.74$, NS $)$. Following the 5 days of PR sessions, mice underwent $1-\mathrm{h}$ extinction trials within a single day until reaching criteria or until the maximum number of trials had been reached (Figure 2d). OSS mice responded persistently during extinction trials, taking a mean of $7.4 \pm 0.4$ sessions to meet extinction criteria, whereas $\mathrm{C}$ mice had much lower responding and met criteria in $2.3 \pm 0.3$ sessions. OSS mice that had gone through extinction sessions following 1- or 6-h FR-1 sessions showed a typical pattern of extinction responding that gradually declined over six sessions (Figure 4d).

\section{OSS is Sensitive to Disruption of Dopaminergic Signaling}

A separate cohort of mice was tested for OSS following pretreatment with the DA receptor antagonist cis-flupenthixol. OSS and control mice first had 14 1-h sessions as described (there was never any consequence of lever pressing in control mice), then were tested following pretreatment with varying doses of cis-flupenthixol in a Latin square design. As baseline responding was different between groups (OSS: $90.0 \pm 25.3$; control: $15.5 \pm 6.2$ ), responses were analyzed as \%baseline responding. There was not a significant main effect of group $(F(1,70)=1.87)$, although there was a main effect of dose $(F(5,70)=12.0$, $p<0.0001)$, and a significant group $\times$ dose interaction $(\mathrm{F}(5,70)=3.30, p=0.01)$. Specifically, low doses of flupenthixol increased active lever pressing in OSS mice (Figure 3a), an effect reported for self-administration of cocaine (Caine and Koob, 1994a; Ahmed and Koob, 2004) and intracranial self-stimulation (ICSS; when using parameters that mimic the kinetics of drug infusions; Lepore and Franklin, 1992). These effects have been interpreted to indicate that DA receptor blockade attenuates the reinforcing efficacy of cocaine and ICSS (Lepore and Franklin, 1992; Caine and Koob, 1994a). DA antagonism does not have this effect on opiate self-administration (Ettenberg et al, 1982), but low doses of opiate antagonist do, consistent with the idea that responding increases to compensate for decreased reinforcing efficacy of the drug (Goldberg et al, 1971; Weeks and Collins, 1976; Ettenberg et al, 1982). Next, D1 null mutant mice were allowed to perform OSS in 14 daily FR-1 sessions. Analysis of active lever pressing revealed significant main effects of genotype $(\mathrm{F}(1,247)=12.9, \quad p<0.01)$ and session $(\mathrm{F}(13,247)=11.2$, $p<0.0001)$ and a significant interaction $(\mathrm{F}(13,247)=5.65$, $p<0.0001)$. Analysis of lever accuracy also showed significant effects of genotype $(\mathrm{F}(1,247)=7.77, p<0.05)$, session $(\mathrm{F}(13,247)=3.50, p<0.0001)$, but not interaction $(\mathrm{F}(13,247)=1.16, \mathrm{NS})$. Compared with WT littermates, D1 null mice did not increase active lever responding (Figure $3 b$ ), nor did they show a preference for the active lever (Figure 3c), consistent with earlier reports of D1 null mice being insensitive to novelty (Holmes et al, 2004). D1 null mice had similar inactive lever presses as WT littermates did during sessions 11-14 (D1 null: 57.8 \pm 20.6 , WT: $37.4 \pm 9.5$, NS), suggesting that lever pressing is not impaired. Additionally, D1 null mice acquired lever 

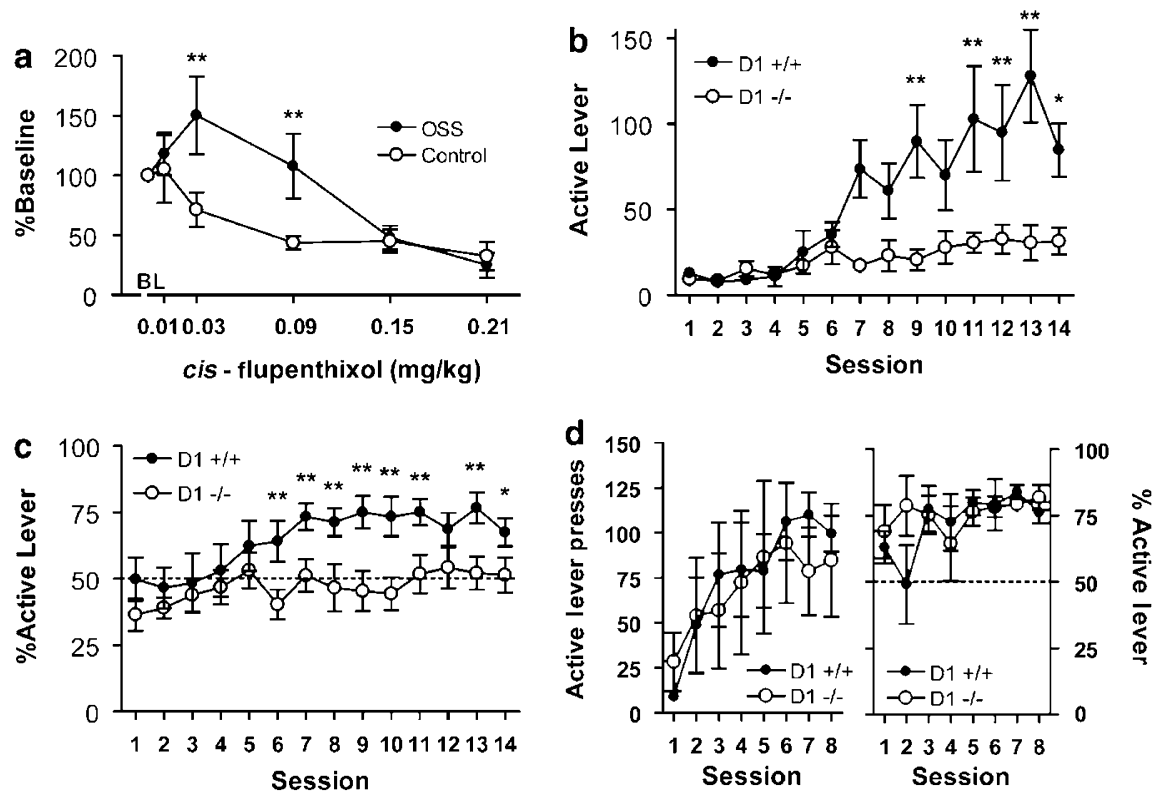

Figure 3 Disruption of dopamine signaling alters OSS. (a) Low doses of cis-flupenthixol increased lever responding in OSS, but not C mice, whereas higher doses attenuated responding in both groups $(n=6-8$, ** $p<0.0 \mathrm{I})$. (b) Dopamine DI null mice do not increase active lever pressing (c) nor do they develop an active lever preference $(n=8-11$, $* p<0.05$, ** $p<0.01$ ). (d) DI null mice increase active lever pressing (left) and develop an active lever preference (right) for food reinforcer $(n=4-5)$.

pressing for food (Figure 3d) as reported previously (Caine et al, 2007).

\section{OSS Persists with Extended Access}

An interesting aspect of the varied stimuli reinforcers used in this study is that there should not be a cumulative effect of the reinforcer itself, ie, there is no drug level that the animal is trying to maintain nor is there a satiety signal following sufficient food consumption. This would suggest that like intracranial self-stimulation studies, levels of responding may be maintained for very long periods of time (Schaefer and Michael, 1992). In fact, sustained responding during extended sessions would indicate that this type of reinforcer would be highly efficacious. A hallmark of drugs of abuse in self-administration studies is that total drug intake increases, and the first hour responding escalates with extended access (Ahmed and Koob, 1998; Roberts et al, 2007). Following OSS acquisition, 10 of the mice were allowed extended access to OSS to determine whether this would (1) increase active lever responding, (2) lead to response escalation during the first hour, or (3) make the mice more resistant to extinction. Analysis of active lever presses revealed a significant effect of session length $(\mathrm{F}(1,171)=8.18$, $p=0.01)$, but no effect of session $(\mathrm{F}(9,171)=1.12$, NS) or interaction $(\mathrm{F}(9,171)=1.12$, NS). When given long access sessions $(6 \mathrm{~h})$, mice responded on the active lever significantly more than the mice given short-term access $(1 \mathrm{~h})$ during several of the sessions (Figure 3a). This resulted in responding at a mean rate of $93.5 \pm 6.2$ presses per hour for mice in the extended access group compared to $82.9 \pm 2.9$ presses per hour for mice in the short access group $(t(12)=1.56$, NS). First hour responding was not significantly different between 1 - and 6-h access mice, as indicated by a lack of effect of session length
$(\mathrm{F}(1,152)=1.97)$, session $(\mathrm{F}(8,152)=0.79)$, or interaction $(\mathrm{F}(8,152)=0.98$; Figure $3 \mathrm{~b})$. The majority of the variance in first hour responding of extended access mice was due to two mice, which responded much more than the group mean (Figure 4c). Comparison of active lever presses during extinction sessions (7-9 days following the last operant session) revealed no significant effect of session length $(\mathrm{F}(1,95)=0.27, \mathrm{NS})$, but there were significant effects of session $(\mathrm{F}(5,95)=9.90, \quad p<0.0001)$ and interaction $(\mathrm{F}(5,95)=2.52, \quad p<0.05)$. Post hoc tests revealed that extended access mice responded significantly more during the first hour than short access mice (Figure 4d).

\section{OSS does Not Correlate with Locomotor Activity in a Novel Environment}

As 'novelty seeking' as measured by locomotor response in a novel open field correlates with operant drug intake (Piazza et al, 1989; Cain et al, 2005; Davis et al, 2008), we investigated the same 'novelty seeking' parameters in relation to OSS. Novel open field locomotor data from 38 of the mice in this study were plotted against operant responses following acquisition (mean active lever presses of sessions 9 and 10). Total distance traveled did not correlate with active lever pressing $\left(r^{2}=4.3 \times 10^{-6}\right.$, Supplementary Figure S2A), and mice grouped as 'high' or 'low' responders by median split of distance traveled had no difference in active lever pressing $(p=0.79$, individuals shown in Supplementary Figure S2B).

\section{DISCUSSION}

Static visual and auditory stimuli have been shown to support operant behavior in rats and mice, with more complex stimuli eliciting greater response (Marx et al, 1955; 

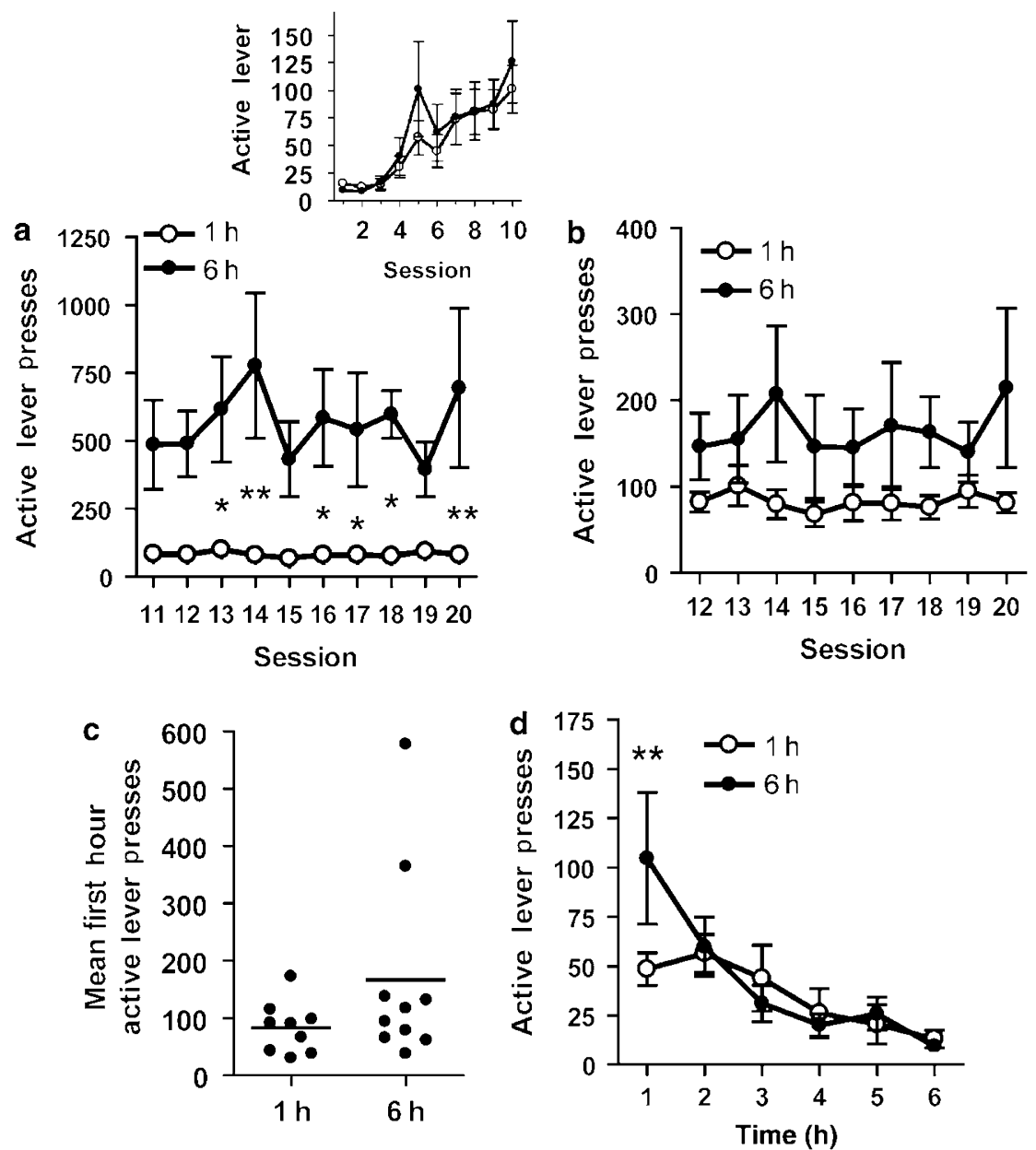

Figure 4 Mice continue responding during extended access. Mice had IO I-h FR-I OSS sessions, and then were assigned to either short (I h) or long $(6 \mathrm{~h})$ access for sessions II-20. (a) Mice responded significantly more in 6-h compared to I-h sessions $(n=9-10$, * $p<0.05$, *** $p<0.0 \mathrm{I})$. (b) First hour responding during sessions II-20 did not differ between groups. (c) Individual means of first hour responding during sessions 19-20. (d) Extinction responding during hourly sessions differed between groups during the first hour only $(* *<0.0 \mathrm{I})$.

Stewart, 1960; Baron and Kish, 1962; Cain et al, 2006) First, we found that a reinforcer without pharmacological effect (such as a drug of abuse) or endogenous motivational drive (such as food or water) supports operant responding, even on a high response requirement (progressive ratio) or after extended access. This expands on earlier studies, which have focused on responding under fixed ratio or fixed interval reinforcement schedules in sessions typically lasting $1 \mathrm{~h}$ or less (Stewart, 1960; Barnes and Baron, 1961; Donny et al, 2003; Cain et al, 2006). Although PR responding for audio and visual stimuli has been reported, this has been performed when investigating the stimuli as conditioned reinforces, not with the stimuli as reinforcers themselves. Specifically, the stimuli had been paired with nicotine or sucrose administration, and controls still received sucrose solution within the testing chamber under conditions of hunger (although unpaired to the cues, they were presented in the same context as the stimuli) (Caggiula et al, 2001; Chaudhri et al, 2006). Additionally, animals in these studies that did not have a history of explicit pairing of the stimuli with sucrose decreased PR responding over subsequent sessions. This lack of PR responding may be due to the consistent nature of the stimuli, as opposed to the dynamic nature of OSS stimuli, or it could be a species difference (rats $v s$ mice). Indeed, in rats that were in social housing conditions, varied visual stimuli did not lead to operant responding (Cain et al, 2006), consistent with the idea that there could be differences in the reinforcing effects of visual and auditory stimuli between rats and mice.

Several of our results show similarities of this reinforcer with psychostimulants, including resistance to extinction, sensitivity to disruptions in DA signaling, and maintained responding with extended access. Although extinction has been examined in regards to operant responding for sensory stimuli, this has been performed in limited duration sessions (Stewart, 1960; Baron and Kish, 1962). The present data suggest that resistance to extinction is seen following responding on both PR and FR-1 schedules of reinforcement in repeated within-day sessions. Next, we found that both pharmacological and genetic disruption of DA signaling altered OSS. Low doses of the DA antagonist cisflupenthixol increased responding for OSS stimuli, an effect that has been previously shown for self-administration of 
cocaine (Ettenberg et al, 1982; Ahmed and Koob, 2004), but not seen heroin (Ettenberg et al, 1982). Mice lacking the D1 DA receptor also failed to acquire operant responding for OSS stimuli, although they acquire operant behavior when food or opiate is the reinforcer (Caine et al, 2007). To our knowledge, this is the first report of interruption of DA signaling affecting the reinforcing effects of sensory stimuli. Next, we compared OSS in mice that were allowed extended access compared to continued short access sessions following acquisition. Earlier studies using sensory stimuli as a reinforcer have focused on relatively short sessions, typically $1 \mathrm{~h}$ or less (Stewart, 1960; Barnes and Baron, 1961; Donny et al, 2003; Cain et al, 2006). Extended access leads to escalated intake of cocaine, amphetamine, and heroin when measured by increased total and hourly intake (Ahmed and Koob, 1998; Ahmed et al, 2000; Kitamura et al, 2006; Rogers et al, 2008). Compared to mice with short access OSS, mice with extended access had elevated total session responding and maintained hourly rates of responding similar to short access mice. However, neither group showed escalated responding compared to their previous performance and extended access mice did not have significantly increased first hour responding relative to short access mice. Thus, extended access to OSS did not result in significant habituation or escalation. It is unclear why high and consistent response rates were maintained during repeated sessions, but with such extensive exposure, 'novelty seeking' is not likely responsible for this persistent behavior. One explanation for the high response rates, especially during extended sessions, could be that responding has transitioned from action-outcome based to stimulus-response (habit) based, whereby performance is repetitive, but no longer goal directed (Adams and Dickinson, 1981; Everitt and Robbins, 2005; Graybiel, 2008). The high levels of extinction responding following OSS suggest this as a possible explanation, although additional experiments including devaluation of OSS stimuli are necessary to properly test this hypothesis. Other explanations for persistent OSS may lie in the lack of food availability during sessions. Concurrent choice experiments show the ability of competing rewards (including chow on the floor of the testing chamber) to decrease responding for other reinforcers (Cousins et al, 1994; Lenoir et al, 2007). It is also possible that extended sessions in the absence of food increases stress and/or hunger, and both of these states have been shown to increase operant responding (Lu et al, 2003). Despite the maintenance of responding throughout extended sessions, escalation was not observed. Although escalation of intake is a characteristic of extended access to psychostimulants and opiates, neuroadaptations that are thought to contribute to addiction are still observed in conditions that do not produce escalation (ie, $1-2 \mathrm{~h}$ drug self-administration sessions). For example, depression in basal NAc glutamate levels (McFarland et al, 2003), altered spine density and morphology in the cortex and NAc (Robinson et al, 2001), and disrupted synaptic plasticity within the ventral tegmental area and NAc (Martin et al, 2006; Chen et al, 2008), all occur following short access drug self-administration sessions. Although OSS mice did not show escalation, this does not preclude the possibility that long-lasting alterations in motivational circuitry could also accompany 'self-administration' of this nondrug reinforcer. Therefore, we suggest that the use of OSS in mice may be an invaluable tool in the study of the behavioral genetics underlying motivational and addiction-related processes.

In this study, we showed that $\mathrm{C} 57 \mathrm{Bl} / 6 \mathrm{~J}$ mice will readily learn an operant response for varied visual stimulation. We found that a reinforcer without pharmacological effect (such as a drug of abuse) or endogenous motivational drive (such as food or water) supports operant responding, even on a high response requirement (progressive ratio). In rats, novelty has been shown to be reinforcing using place conditioning (Bardo et al, 1989; Besheer et al, 1999), and static visual stimuli support operant behavior on fixed ratios of reinforcement (Marx et al, 1955; Stewart, 1960; Baron and Kish, 1962). In primates, operant responses will be maintained for visual stimuli (Butler, 1961), and responding increases as they become more dynamic (Blatter and Schultz, 2006). Dynamic visual stimuli have also been shown to support operant behavior in rats, but there is a significant effect on rearing conditions (Cain et al, 2006). As environmental enrichment has been shown to increase habituation to novel stimuli (Zimmermann et al, 2001), it may be expected that increasing housing enrichment may attenuate OSS. Consistent with this, rats that were reared in an isolated environment acquired operant responding for dynamic visual stimuli, whereas those reared in socially and environmentally enriched housing did not (Cain et al, 2006). In this study, mice were not environmentally enriched (no novel or complex objects were included in housing), but were socially housed ( $2-5$ mice per cage). An interesting question that remains is whether isolation will increase or further environmental enrichment will decrease OSS responding in mice. We found that fixed ratio responding (lever presses and accuracy) is comparable to levels we have reported previously for cocaine (Grueter et al, 2006) in this strain, and responding for varied visual stimuli is maintained on the same PR schedule that supports cocaine self-administration in mice (Colby et al, 2003; Olsen and Winder, 2006). Cis-flupenthixol has been shown to induce rightward shifts in the dose-response curve of FR-1 self-administered cocaine, resulting in an increase in responding with low antagonist doses and a depression of responding with high doses (Ahmed and Koob, 2004). This trend was observed in this study using OSS, suggesting that the visual stimuli are not near a reinforcement threshold; rather, there is a measurable decrease in reinforcing efficacy (resulting in higher lever pressing) before it becomes subthreshold. This idea is supported by performance on the PR schedule of reinforcement.

It is difficult to directly compare novelty/sensation seeking between humans and rodents. A key aspect of novelty or sensation seeking between both species, however, is that there is a theoretical spectrum of stimuli, where low- and high-intensity stimuli elicit an avoidance response (ie, boredom and fear, respectively), and optimal stimuli elicit approach behavior (ie, approach or engaging in an activity; for example, see Hughes(2007). Although the mice in the OSS task are not pursuing the same stimuli as humans, the OSS stimuli elicit approach and are reinforcing as evidenced by acquisition and maintenance of an operant response. 
There has been a recent trend toward considering behavioral addictions (such as pathological gambling or compulsive eating) to be highly similar to substance abuse and dependence (Wang et al, 2004; Volkow and Wise, 2005; Grant et al, 2006). Behavioral addictions fit the classical definition of addiction that includes engaging in the behavior despite serious negative consequences (Holden, 2001; Hyman et al, 2006), and manifest in similar psychological and behavioral patterns, including craving, impaired control over the behavior, tolerance, withdrawal, and high relapse rates (Marks, 1990; Lejoyeux et al, 2000; National Institute on Drug Abuse (NIDA) et al, 2002; Potenza, 2006). These patterns suggest that neuroadaptations similar to those induced by drugs of abuse may be occurring, even in the absence of a pharmacological reinforcer. The present data also provide evidence that addictions involving nondrug reinforcers may have similar neural underpinnings as drug addiction. As OSS does not use a pharmacological reinforcer and leads to both reinforced behavior and seeking, it could have high face validity for the study of behavioral addictions. OSS is not designed to model behavioral addictions per se, but it results in motivated and persistent behavior, which is not driven by a pharmacological or food reinforcer. Thus, OSS may be a novel early step in identifying substrates specific to behavioral addictions in humans.

The trait of novelty or sensation seeking has been associated with increased drug use in numerous human populations (Zuckerman, 1986; Cloninger, 1987; Jaffe and Archer, 1987). Rodent models of novelty seeking have also revealed a similar trend, as novelty seeking correlates with the degree of drug reinforcement in individuals (Piazza et al, 1989; Klebaur and Bardo, 1999). There are also other indications that the reinforcing effects of novelty are mediated by some of the same neural substrates as drugs of abuse. Exposure to a novel environment has additive effects with cocaine on locomotor activation, and immediate early gene expression (Badiani et al, 1998) and visual stimuli (similar to those used in this study, but static) are synergistic with nicotine in operant reinforcement (Caggiula et al, 2001). Further, exposure to novel stimuli can compete with the reinforcing effects of psychostimulants in self-administration and conditioned place preference (Bardo et al, 2001; Reichel and Bevins, 2008). We found that pharmacological and genetic disruption of DA signaling was capable of altering the reinforcing value of dynamic stimuli, suggesting that the neural substrates may be more similar to psychostimulants than food. It is unlikely that DA disruption had a nonspecific effects on operant responding (except at high doses of antagonist), as DA is not critical for acquisition of an operant task, especially when task requirements are low (Holmes et al, 2004; Salamone, 2007). Additionally, inactive lever pressing on session 1 was comparable between D1 null and WT mice (15.0 \pm 4.9 and $16.7 \pm 4.5$, respectively), suggesting that lever pressing was not impaired in these mice. This study lends further support to the idea that novelty/sensation seeking is closely related to drug seeking and that OSS can be used to study processes relevant to drug and other addictions.

We also found that mice were resistant to extinction, as they exhibited high levels of 'seeking' behavior during extinction sessions (Figures $2 \mathrm{~d}$ and $4 \mathrm{~d}$ ). At first glance, it may be tempting to consider the high first hour extinction responding in long access mice relative to short access ones as the 'incubation' effects on seeking as reported for cocaine (Grimm et al, 2001). A comparison of first hour responding of these same mice during extended access to the reinforcer, however, reveals that first hour extinction values are not significantly different than the last operant session before extinction. Interestingly, short access mice had significantly lower responding in the first hour of extinction relative to their last operant session $(p<0.01)$. Nonetheless, mice with either short or long access experience still had greater extinction responding than control mice. In fact, mice in this study showed levels of 'seeking' (extinction responding) similar to or greater than other studies following cocaine (Fuchs et al, 2003; Mead et al, 2007) or methamphetamine (Yan et al, 2006) self-administration in C57 mice. This behavioral persistence is a hallmark of animals following drug self-administration and provides further evidence that this method may have predictive validity for screening treatments for drugs of abuse (ie, can treatment reduce the reinforcing effects of novelty or subsequent seeking behavior?).

\section{ACKNOWLEDGEMENTS}

We thank Gregg Stanwood, PhD for providing breeding pairs of D1-deficient mice. This work was supported by the National Institute on Drug Abuse (DGW; DA19112) and by the National Institute of Mental Health via a Neurogenomics Training Grant (CMO).

\section{DISCLOSURE/CONFLICTS OF INTEREST}

Christopher Olsen and Danny Winder have no conflicts of interest.

\section{REFERENCES}

Adams CD, Dickinson A (1981). Instrumental reponding following reinforcer devaluation. Q J Exp Psychol 33B: 109-121.

Ahmed SH, Koob GF (1998). Transition from moderate to excessive drug intake: change in hedonic set point. Science 282: 298-300.

Ahmed SH, Koob GF (2004). Changes in response to a dopamine receptor antagonist in rats with escalating cocaine intake. Psychopharmacology 172: 450-454.

Ahmed SH, Walker JR, Koob GF (2000). Persistent increase in the motivation to take heroin in rats with a history of drug escalation. Neuropsychopharmacology 22: 413-421.

Badiani A, Oates MM, Day HE, Watson SJ, Akil H, Robinson TE (1998). Amphetamine-induced behavior, dopamine release, and c-fos mRNA expression: modulation by environmental novelty. J Neurosci 18: 10579-10593.

Bardo MT, Klebaur JE, Valone JM, Deaton C (2001). Environmental enrichment decreases intravenous self-administration of amphetamine in female and male rats. Psychopharmacology (Berl) 155: 278-284.

Bardo MT, Neisewander JL, Pierce RC (1989). Novelty-induced place preference behavior in rats: effects of opiate and dopaminergic drugs. Pharmacol Biochem Behav 32: 683-689.

Barnes GW, Baron A (1961). The effects of sensory reinforcement on extinction behavior. J Comp Physiol Psychol 54: 461-465. 
Baron A, Kish GB (1962). Low-intensity auditory and visual stimuli as reinforcers for the mouse. J Comp Physiol Psychol 55: 1011-1013.

Bassareo V, De Luca MA, Di Chiara G (2002). Differential expression of motivational stimulus properties by dopamine in nucleus accumbens shell $v s$ core and prefrontal cortex. J Neurosci 22: 4709-4719.

Besheer J, Jensen HC, Bevins RA (1999). Dopamine antagonism in a novel object recognition and a novel-object place conditioning preparation with rats. Behav Brain Res 103: 35-44.

Blatter K, Schultz W (2006). Rewarding properties of visual stimuli. Exp Brain Res 168: 541-546.

Butler RA (1961). The responsiveness of Rhesus monkeys to motion pictures. J Genet Psychol 98: 239-245.

Caggiula AR, Donny EC, White AR, Chaudhri N, Booth S, Gharib MA et al (2001). Cue dependency of nicotine self-administration and smoking. Pharmacol Biochem Behav 70: 515-530.

Cain ME, Green TA, Bardo MT (2006). Environmental enrichment decreases responding for visual novelty. Behav Processes 73: 360-366.

Cain ME, Saucier DA, Bardo MT (2005). Novelty seeking and drug use: contribution of an animal model. Exp Clin Psychopharmacol 13: $367-375$.

Caine SB, Koob GF (1994a). Effects of dopamine D-1 and D-2 antagonists on cocaine self-administration under different schedules of reinforcement in the rat. J Pharmacol Exp Ther 270: $209-218$.

Caine SB, Koob GF (1994b). Effects of mesolimbic dopamine depletion on responding maintained by cocaine and food. $J$ Exp Anal Behav 61: 213-221.

Caine SB, Thomsen M, Gabriel KI, Berkowitz JS, Gold LH, Koob GF et al (2007). Lack of self-administration of cocaine in dopamine D1 receptor knock-out mice. J Neurosci 27: 13140-13150.

Chaudhri N, Caggiula AR, Donny EC, Booth S, Gharib M, Craven L et al (2006). Operant responding for conditioned and unconditioned reinforcers in rats is differentially enhanced by the primary reinforcing and reinforcement-enhancing effects of nicotine. Psychopharmacology (Berl) 189: 27-36.

Chen BT, Bowers MS, Martin M, Hopf FW, Guillory AM, Carelli $\mathrm{RM}$ et al (2008). Cocaine but not natural reward selfadministration nor passive cocaine infusion produces persistent LTP in the VTA. Neuron 59: 288-297.

Cloninger CR (1987). Neurogenetic adaptive mechanisms in alcoholism. Science 236: 410-416.

Colby CR, Whisler K, Steffen C, Nestler EJ, Self DW (2003). Striatal cell type-specific overexpression of DeltaFosB enhances incentive for cocaine. J Neurosci 23: 2488-2493.

Cousins MS, Wei W, Salamone JD (1994). Pharmacological characterization of performance on a concurrent lever pressing/feeding choice procedure: effects of dopamine antagonist, cholinomimetic, sedative and stimulant drugs. Psychopharmacology (Berl) 116: 529-537.

Davis BA, Clinton SM, Akil H, Becker JB (2008). The effects of novelty-seeking phenotypes and sex differences on acquisition of cocaine self-administration in selectively bred High-Responder and Low-Responder rats. Pharmacol Biochem Behav 90: 331-338.

de Wit H, Stewart J (1981). Reinstatement of cocaine-reinforced responding in the rat. Psychopharmacology (Berl) 75: 134-143.

de Wit H, Stewart J (1983). Drug reinstatement of heroinreinforced responding in the rat. Psychopharmacology (Berl) 79: $29-31$

Di Chiara G, Bassareo V, Fenu S, De Luca MA, Spina L, Cadoni C et al (2004). Dopamine and drug addiction: the nucleus accumbens shell connection. Neuropharmacology 47(Suppl 1): 227-241.

Donny EC, Chaudhri N, Caggiula AR, Evans-Martin FF, Booth S, Gharib MA et al (2003). Operant responding for a visual reinforcer in rats is enhanced by noncontingent nicotine: implications for nicotine self-administration and reinforcement. Psychopharmacology (Berl) 169: 68-76.

Dworkin SI, Guerin GF, Co C, Goeders NE, Smith JE (1988). Lack of an effect of 6-hydroxydopamine lesions of the nucleus accumbens on intravenous morphine self-administration. Pharmacol Biochem Behav 30: 1051-1057.

Ettenberg A, Pettit HO, Bloom FE, Koob GF (1982). Heroin and cocaine intravenous self-administration in rats: mediation by separate neural systems. Psychopharmacology (Berl) 78: 204-209.

Everitt BJ, Robbins TW (2005). Neural systems of reinforcement for drug addiction: from actions to habits to compulsion. Nat Neurosci 8: 1481-1489.

Fuchs RA, See RE, Middaugh LD (2003). Conditioned stimulusinduced reinstatement of extinguished cocaine seeking in C57BL/6 mice: a mouse model of drug relapse. Brain Res 973: 99-106.

Goldberg SR, Woods JH, Schuster CR (1971). Nalorphine-induced changes in morphine self-administration in rhesus monkeys. $J$ Pharmacol Exp Ther 176: 464-471.

Grant JE, Brewer JA, Potenza MN (2006). The neurobiology of substance and behavioral addictions. CNS Spectr 11: 924-930.

Graybiel AM (2008). Habits, rituals, and the evaluative brain. Annu Rev Neurosci 31: 359-387.

Grimm JW, Hope BT, Wise RA, Shaham Y (2001). Neuroadaptation. Incubation of cocaine craving after withdrawal. Nature 412: 141-142.

Grueter BA, Gosnell HB, Olsen CM, Schramm-Sapyta NL, Nekrasova T, Landreth GE et al (2006). Extracellular-signal regulated kinase 1-dependent metabotropic glutamate receptor 5 -induced long-term depression in the bed nucleus of the stria terminalis is disrupted by cocaine administration. J Neurosci 26: $3210-3219$.

Holden C (2001). 'Behavioral' addictions: do they exist? Science 294: $980-982$.

Holmes A, Lachowicz JE, Sibley DR (2004). Phenotypic analysis of dopamine receptor knockout mice; recent insights into the functional specificity of dopamine receptor subtypes. Neuropharmacology 47: 1117-1134.

Hughes RN (2007). Neotic preferences in laboratory rodents: issues, assessment and substrates. Neurosci Biobehav Rev 31: 441-464.

Hyman SE, Malenka RC, Nestler EJ (2006). Neural mechanisms of addiction: the role of reward-related learning and memory. Ann Rev Neurosci 29: 565-598.

Jaffe LT, Archer RP (1987). The prediction of drug use among college students from MMPI, MCMI, and sensation seeking scales. J Pers Assess 51: 243-253.

Kitamura O, Wee S, Specio SE, Koob GF, Pulvirenti L (2006). Escalation of methamphetamine self-administration in rats: a dose-effect function. Psychopharmacology (Berl) 186: 48-53.

Klebaur JE, Bardo MT (1999). Individual differences in novelty seeking on the playground maze predict amphetamine conditioned place preference. Pharmacol Biochem Behav 63: 131-136.

Lejoyeux M, Mc Loughlin M, Adès J (2000). Epidemiology of behavioral dependence: literature review and results of original studies. Eur Psychiatry 15: 129-134.

Lenoir M, Serre F, Cantin L, Ahmed SH (2007). Intense sweetness surpasses cocaine reward. PLOS ONE 2: e698.

Lepore M, Franklin KB (1992). Modelling drug kinetics with brain stimulation: dopamine antagonists increase self-stimulation. Pharmacol Biochem Behav 41: 489-496.

Lu L, Shepard JD, Hall FS, Shaham Y (2003). Effect of environmental stressors on opiate and psychostimulant reinforcement, reinstatement and discrimination in rats: a review. Neurosci Biobehav Rev 27: 457-491.

Marks I (1990). Behavioural (non-chemical) addictions [see comment]. Br J Addict 85: 1389-1394. 
Martin M, Chen BT, Hopf FW, Bowers MS, Bonci A (2006). Cocaine self-administration selectively abolishes LTD in the core of the nucleus accumbens. Nat Neurosci 9: 868-869.

Marx MH, Henderson RL, Roberts CL (1955). Positive reinforcement of the bar-pressing response by a light stimulus following dark operant pretests with no after effect. J Comp Physiol Psychol 48: 73-76.

McFarland K, Lapish CC, Kalivas PW (2003). Prefrontal glutamate release into the core of the nucleus accumbens mediates cocaineinduced reinstatement of drug-seeking behavior. J Neurosci 23: 3531-3537.

Mead AN, Zamanillo D, Becker N, Stephens DN (2007). AMPAreceptor GluR1 subunits are involved in the control over behavior by cocaine-paired cues. Neuropsychopharmacology 32: 343-353.

Mitchell JB, Gratton A (1992). Partial dopamine depletion of the prefrontal cortex leads to enhanced mesolimbic dopamine release elicited by repeated exposure to naturally reinforcing stimuli. J Neurosci 12: 3609-3618.

National Institute on Drug Abuse (NIDA), National Institute of Mental Health (NIMH) and National Institute of Diabetes and Digestive and Kidney Diseases (NIDDK) (2002). Reward and decision making: opportunities and future directions. Neuron 36: $189-192$

O’Brien CP, Gardner EL (2005). Critical assessment of how to study addiction and its treatment: human and non-human animal models. Pharmacol Ther 108: 18-58.

Olsen CM, Winder DG (2006). A method for single-session cocaine self-administration in the mouse. Psychopharmacology (Berl) 187: 13-21.

Piazza PV, Deminiere JM, Le Moal M, Simon H (1989). Factors that predict individual vulnerability to amphetamine self-administration. Science 245: 1511-1513.

Pierce RC, Crawford CA, Nonneman AJ, Mattingly BA, Bardo MT (1990). Effect of forebrain dopamine depletion on noveltyinduced place preference behavior in rats. Pharmacol Biochem Behav 36: 321-325.

Pontieri FE, Tanda G, Di Chiara G (1995). Intravenous cocaine, morphine, and amphetamine preferentially increase extracellular dopamine in the 'shell' as compared with the 'core' of the rat nucleus accumbens. Proc Natl Acad Sci USA 92: 12304-12308.

Potenza MN (2006). Should addictive disorders include nonsubstance-related conditions? Addiction 101(Suppl 1): 142-151.

Rebec GV, Christensen JR, Guerra C, Bardo MT (1997). Regional and temporal differences in real-time dopamine efflux in the nucleus accumbens during free-choice novelty. Brain Res 776: 61-67.
Reichel CM, Bevins RA (2008). Competition between the conditioned rewarding effects of cocaine and novelty. Behav Neurosci 122: $140-150$.

Roberts DC, Morgan D, Liu Y (2007). How to make a rat addicted to cocaine. Prog Neuropsychopharmacol Biol Psychiatry 31: $1614-1624$

Robinson TE, Gorny G, Mitton E, Kolb B (2001). Cocaine selfadministration alters the morphology of dendrites and dendritic spines in the nucleus accumbens and neocortex. Synapse 39: 257-266.

Rogers JL, De Santis S, See RE (2008). Extended methamphetamine self-administration enhances reinstatement of drug seeking and impairs novel object recognition in rats. Psychopharmacology (Berl) 199: 615-624.

Salamone JD (2007). Functions of mesolimbic dopamine: changing concepts and shifting paradigms. Psychopharmacology (Berl) 191: 389.

Schaefer GJ, Michael RP (1992). Schedule-controlled brain selfstimulation: has it utility for behavioral pharmacology? Neurosci Biobehav Rev 16: 569-583.

Schramm-Sapyta NL, Olsen CM, Winder DG (2006). Cocaine selfadministration reduces excitatory responses in the mouse nucleus accumbens shell. Neuropsychopharmacology 31: 1444-1451.

Stanwood GD, Parlaman JP, Levitt P (2005). Anatomical abnormalities in dopaminoceptive regions of the cerebral cortex of dopamine D1 receptor mutant mice. J Comp Neurol 487: 270-282.

Stewart J (1960). Reinforcing effects of light as a function of intensity and reinforcement schedule. J Comp Physiol Psychol 53: 187-193.

Volkow ND, Wise RA (2005). How can drug addiction help us understand obesity? Nat Neurosci 8: 555-560.

Wang GJ, Volkow ND, Thanos PK, Fowler JS (2004). Similarity between obesity and drug addiction as assessed by neurofunctional imaging: a concept review. J Addict Dis 23: 39-53.

Weeks JR, Collins RJ (1976). Changes in morphine self-administration in rats induced by prostaglandin E1 and naloxone. Prostaglandins 12: 11-19.

Yan Y, Nitta A, Mizoguchi H, Yamada K, Nabeshima T (2006). Relapse of methamphetamine-seeking behavior in C57BL/6] mice demonstrated by a reinstatement procedure involving intravenous self-administration. Behav Brain Res 168: 137-143.

Zimmermann A, Stauffacher M, Langhans W, Wurbel H (2001). Enrichment-dependent differences in novelty exploration in rats can be explained by habituation. Behav Brain Res 121: 11-20.

Zuckerman M (1986). Sensation seeking and the endogenous deficit theory of drug abuse. NIDA Res Monogr 74: 59-70.

Supplementary Information accompanies the paper on the Neuropsychopharmacology website (http://www.nature.com/npp) 